\title{
A comparative study on outcome of conservative and surgical treatment of type III supracondylar fracture of humerus in children
}

\author{
Vinay N., Manjunatha A.*, Anand Kumar B. S.
}

Department of Orthopaedics, Kodagu Institute of Medical Sciences, Madikeri, Karnataka, India

Received: 14 May 2020

Revised: 28 May 2020

Accepted: 29 May 2020

\author{
*Correspondence: \\ Dr. Manjunatha A., \\ E-mail: dr.anjan4u@gmail.com
}

Copyright: ( $)$ the author(s), publisher and licensee Medip Academy. This is an open-access article distributed under the terms of the Creative Commons Attribution Non-Commercial License, which permits unrestricted non-commercial use, distribution, and reproduction in any medium, provided the original work is properly cited.

\begin{abstract}
Background: Supracondylar fracture of humerus is most common of all the fractures around the elbow in children. They occur most commonly in children more so in male child with the peak around 5-8 years. Objective of this study was to compare the outcome of 3 different modalities of treatment for supracondylar fracture of humerus.

Methods: Children with type III supracondylar fracture of humerus were categorized into group A, group B, group C based on conservative, closed reduction and percutaneous $\mathrm{K}$ wire fixation and open reduction and $\mathrm{K}$ wire fixation modalities of treatment given. All the children were followed for 6 months and the outcome of treatment was evaluated using Flynn's criteria.

Results: 40 children were treated with 3 different modalities of treatment. The rate of complications was less in children who were operated on first day of admission ( $\mathrm{p}=0.02$ ). Group B and group C had $80 \%$ and $61.11 \%$ excellent results and group A had $47.05 \%$ poor results. The outcome was better with cross K wire pinning than lateral pinning $(\mathrm{p}=0.015)$. Conclusions: Supracondylar fracture of humerus should be operated as early as possible to reduce the rate of complications. The outcome of surgical treatment was better than conservative treatment evaluated in terms of Flynn's criteria. Cross wire pinning was better than lateral pinning in terms of outcome, but the rate of neuropraxias was more with cross wire pinning.
\end{abstract}

Keywords: Supracondylar humerus fractures, Elbow, Kirschner wires, Open fracture reduction, Conservative treatment

\section{INTRODUCTION}

Supracondylar fracture of humerus constitutes about $55 \%$ to $75 \%$ of all the fractures around the elbow in children. ${ }^{1}$ They occur most commonly during the childhood with the peak around 5-8 years. Boys are most commonly affected in the non-dominant side. ${ }^{2}$ Supracondylar fracture of humerus is a highly complicated fracture if not treated properly it leads to neurovascular injury, malunion and elbow stiffness.

Undisplaced type I supracondylar fracture require simple immobilization of the elbow in above elbow plaster of Paris (POP) slab with the elbow in $90^{\circ}$ flexion. Even type
II fractures are treated conservatively with closed reduction and POP slab. There are various treatment options for type III fracture which include closed reduction with POP, closed reduction with skeletal traction, closed reduction with percutaneous pinning, open reduction with percutaneous $\mathrm{K}$ wire fixation. ${ }^{3}$ The traditional conservative method of closed reduction and POP slab application has various challenges which include difficulty in reduction and maintenance of reduction post manipulation of fracture. Most of the patients had malunion and elbow stiffness during follow up of this traditional method of treatment. A better understanding of bio-mechanics, quality of implants, principles of internal fixation, soft tissue care, antibiotics and asepsis have all 
contributed to the radical changes in the treatment modalities of supracondylar fractures in children. ${ }^{4}$

So, the other treatment options for displaced supracondylar fractures of the humerus include closed reduction with percutaneous pinning or open reduction with internal fixation. Surgical treatment of the displaced supracondylar fractures has its principal advantages: more stable fixation, better anatomical and functional outcome. ${ }^{5}$ Our study is entitled to compare the outcome of conservative and surgical treatment of supracondylar fracture of the humerus by analysing range of motion and carrying angle using Flynn's criteria during the follow up of the patients.

\section{METHODS}

A prospective observational comparative study conducted among the patients admitted in Kodagu Institute of Medical Sciences, Madikeri with supracondylar fracture of humerus considering the inclusion and exclusion criteria. The study period was for 1 year conducted from April 2019 to March 2020. The institutional ethical committee clearance was taken before the start of this study.

\section{Inclusion criteria}

Inclusion criteria were all children upto 14 years of age with closed supracondylar fractures of humerus.

\section{Exclusion criteria}

Exclusion criteria were all children of age more than 14 years, all open fractures, and cases associated with other fractures around elbow.

\section{Methodology}

All the children attending our OPD/emergency with history of fall on outstretched hand and presenting with injury to elbow were examined for the soft tissue swelling, ecchymosis, skin puckering, deformity, punctured wound, fracture and any evidence of compartment syndrome. Vascular and neurological status of the extremity were thoroughly assessed. X-rays were taken in two planes, lateral and AP view and the presence of supracondylar fracture noted. In some instances when a supracondylar fracture was suspected but not visualized on the routine anteroposterior and lateral views, an oblique view was taken to assess the fracture line.

The supracondylar fracture was classified according to Gartland's classification as class I/II/III (Table 1). ${ }^{6}$ The children with type I non-displaced fractures were treated conservatively with above elbow POP slab with the elbow in $90^{\circ}$ flexion and pronation. Type II displaced fracture with intact posterior cortex was also treated conservatively after closed manipulation and reduction. Children with type III supracondylar fracture were included in this study and grouped according to the treatment given to them. Group A children treated with closed reduction and POP slab application, group $\mathrm{B}$ with closed reduction and percutaneous pin fixation and group $\mathrm{C}$ with open reduction and internal fixation. All the surgical procedures were done under general anaesthesia. Post-operatively child was monitored for neurovascular deficit and treated with antibiotics and analgesics. On post-operative day 1 and after 1 week, post op X-rays were taken to determine the maintenance of reduction. After 3 weeks, the POP slab was removed and active range of motion exercises were encouraged. Patient was warned to avoid massage and passive stretching of elbow joint. The $\mathrm{K}$ wires were removed after 4 to 6 weeks.

\section{Table 1: Gartland's classification of supracondylar fracture of humerus. ${ }^{6}$}

\begin{tabular}{|ll|}
\hline Type & Classifications \\
\hline Type I & Undisplaced \\
\hline Type II & Displaced (with intact posterior cortex) \\
\hline \multirow{3}{*}{ Type III } & Displaced \\
\cline { 2 - 2 } & Posteromedial \\
\cline { 2 - 2 } & Posterolateral \\
\hline
\end{tabular}

Regular follow up was done every month for a period of 6 months. The patients were examined clinically and radiologically, assessed for any complications, range of motion and carrying angle using Flynn's criteria (Table 2). The results were graded as excellent, good, fair and poor according to loss of range of motion and loss of carrying angle.

The results were compared between groups and analysed. Chi-square test was used for comparing the outcome between conservative and surgical treatment using SPSS software and $\mathrm{p}<0.05$ was considered as significant.

Table 2: Flynn's criteria for assessing the range of motion and loss of carrying angle. ${ }^{3}$

\begin{tabular}{|llll|}
\hline \multirow{2}{*}{ Result } & Rating & $\begin{array}{l}\text { Cosmetic factor: carrying angle loss } \\
\text { (degrees) }\end{array}$ & $\begin{array}{l}\text { Functional factor: motion loss } \\
\text { (degrees) }\end{array}$ \\
\hline \multirow{2}{*}{ Satisfactory } & Excellent & $0-5$ & $0-5$ \\
\cline { 2 - 4 } & Good & $6-10$ & $6-10$ \\
\cline { 2 - 4 } & Fair & $11-15$ & $11-15$ \\
\hline Unsatisfactory & Poor & $>15$ & $>15$ \\
\hline
\end{tabular}




\section{RESULTS}

In this study, totally 60 patients were diagnosed with supracondylar fracture but 17 children were excluded from the study as they don't fit into the inclusion criteria. Out of 43, 3 patients were lost for follow-up, so finally 40 patients were included in this study. In this study, 3 (7.5\%) children were $<4$ years of age, $28(70 \%)$ of patients were between 4-8 years, $8(20 \%)$ between $8-12$ years and $1(2.5 \%)$ child was >12-14 years of age. Majority of the children were males i.e., $25(62.50 \%)$ and $15(37.50 \%)$ children were females (Table 3). In this study, the most common cause of injury was fall while playing (sports related injury) which was seen in $30(75 \%)$ patients, followed by fall from height in $10(25 \%)$ patients. In this study, $32(80 \%)$ patients sustained fracture on left side and 8 patients $(20 \%)$ had on right side.

All the 40 fractures were type III closed extension type of fractures (Figure 1). No vascular compromise or compartmental syndrome was seen in any of the cases of supracondylar fractures. In this study, 17 cases belong to group A who were managed conservatively with closed reduction and POP slab, 5 cases were group B who were treated with closed reduction and $\mathrm{K}$ wire fixation and group $\mathrm{C}$ had 18 cases operated surgically with open reduction and $\mathrm{K}$ wire fixation (Figure 2 ). In all these 23 patients who were treated surgically, cross $\mathrm{K}$ wire pinning was done in 19 cases and lateral $\mathrm{K}$ wire pinning was done in 4 case (Figure 3). 13 (56.52\%) cases were operated on first day of admission, $6(26.08 \%)$ cases were done on $2^{\text {nd }}$ day and $4(17.39 \%)$ cases on $3^{\text {rd }}$ day.

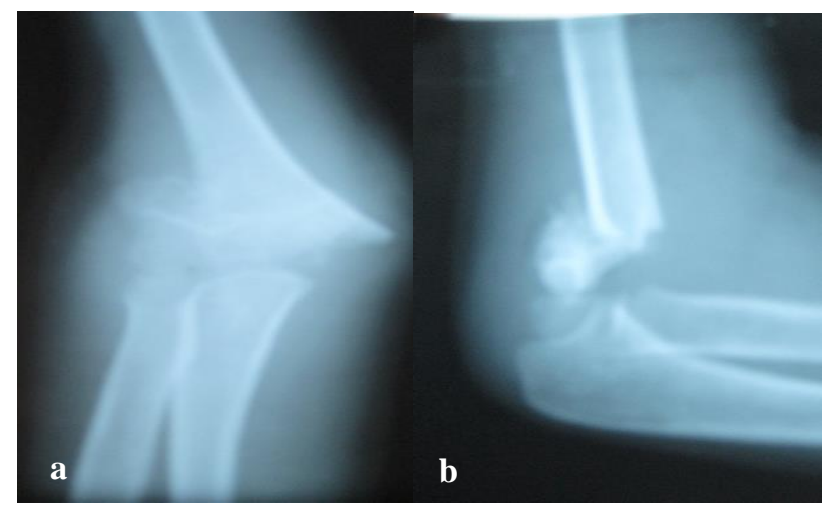

Figure 1: X-ray showing the type III extension type supracondylar fracture of humerus; (a) AP view and (b) lateral view.

In this study, 3 patients had radial nerve injury. 2 cases of radial nerve injury were iatrogenic occurred during open reduction and 1 case was seen in conservatively treated child. Intra-operatively 5 patients had iatrogenic ulnar nerve palsy and all these 5 cases were seen in open reduction cases. All the 8 patients with radial and ulnar nerve palsy had progressive improvement with full functional recovery in 4-6 months of follow up. Postoperatively 3 children had superficial pin tract infection occurred in open reduction and percutaneous cross $\mathrm{K}$ wire fixation cases which was treated with antibiotics and subsided. During the 6 months follow up of all the 40 patients, 9 patients developed cubitus varus deformity. Among these 8 patients were treated conservatively with closed reduction and POP slab and 1 with open reduction.

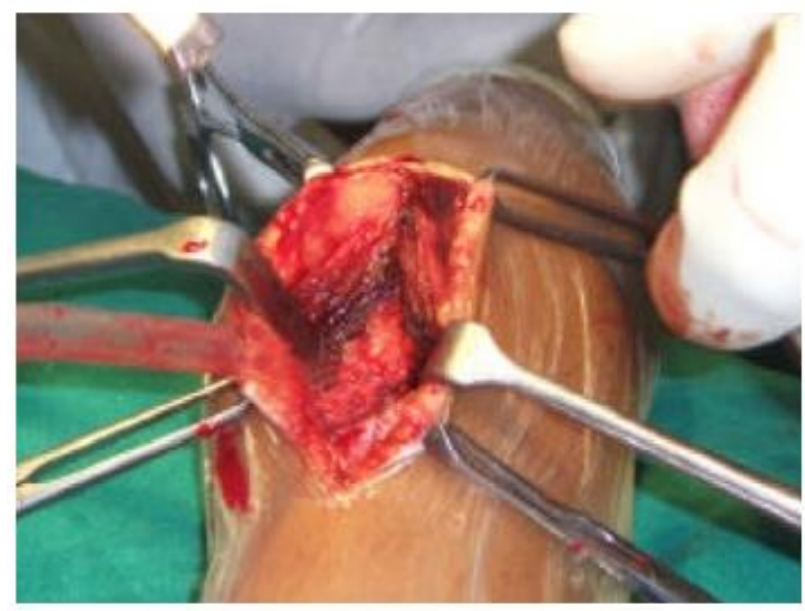

Figure 2: Intra-operative picture shows open reduction.

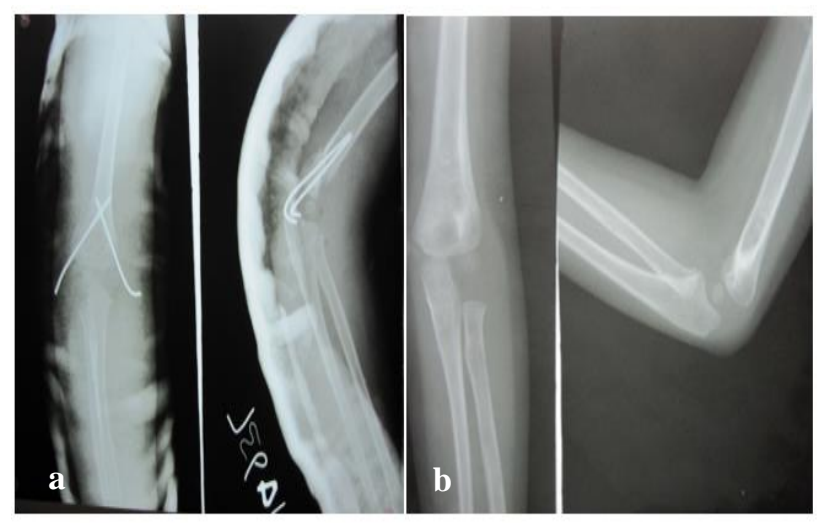

Figure 3: (a) Post-operative and (b) follow up pictures showing AP and lateral view X-ray showing cross $\mathrm{K}$ wire pinning.

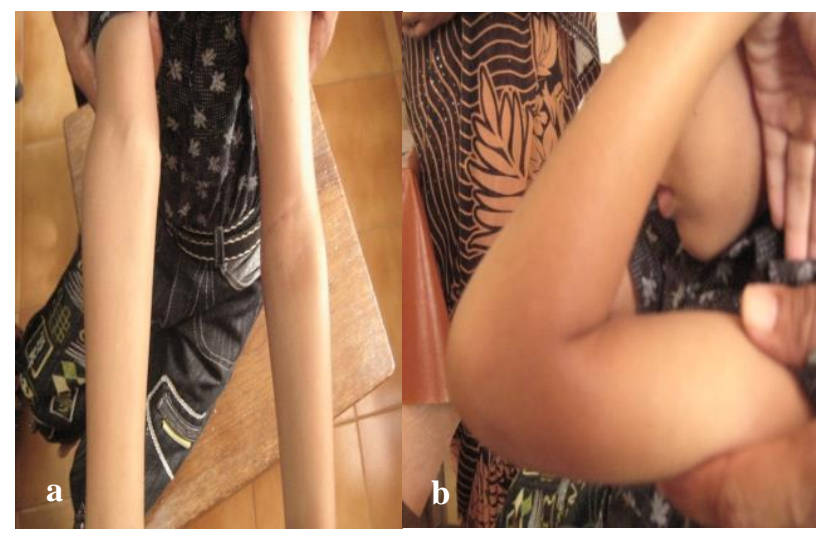

Figure 4: The child with (a) cubitus varus deformity and (b) loss of range of movements. 
Table 3: Age and sex distribution of children with supracondylar fracture of humerus.

\begin{tabular}{|lllllc|}
\hline Sex & Age group (in years) & & & Total \\
\hline Male child & $<\mathbf{4}$ & $\mathbf{4 - 8}$ & $\mathbf{9 - 1 2}$ & $\mathbf{1 3 - 1 4}$ & 25 \\
\hline Female child & 2 & 17 & 5 & 1 & 15 \\
\hline Total & 1 & 11 & 3 & 0 & 40 \\
\hline
\end{tabular}

Table 4: Comparison between conservative and surgical method of treatment of supracondylar fracture of humerus.

\begin{tabular}{|lllllll|}
\hline $\begin{array}{l}\text { Type of } \\
\text { fracture }\end{array}$ & Treatment & Excellent & Good & Fair & Poor & Total \\
\hline Type III & Conservative (group A) & - & 4 & 5 & 8 & 17 \\
\cline { 2 - 7 } & Surgical (group B and C) & 15 & 5 & 2 & 1 & 23 \\
\hline Total & & 15 & 9 & 7 & 9 & 40 \\
\hline Total (\%) & & 37.5 & 22.5 & 17.5 & 22.5 & 100 \\
\hline
\end{tabular}

$\mathrm{P}=0.0013$.

In this study all the fractures were united in 4-6 weeks. All the 40 patients were followed regularly and loss of carrying angle and motion loss was calculated at the end of 6 months of follow up. In this study out of 40 patients, 15 patients $(37.5 \%)$ had loss of range of motion of $0-5^{\circ}, 9$ patients $(22.5 \%)$ had $6-10^{\circ}, 7$ patients $(17.5 \%)$ had $11-15^{\circ}$ and 9 patients $(22.5 \%)$ had $>15^{\circ}$ of range of motion. In our study of 40 patients, 15 patients $(37.5 \%)$ had loss of carrying angle of $0-5^{\circ}, 9$ patients $(22.5 \%)$ had loss of carrying angle $6-10^{\circ}, 7$ patients $(17.5 \%)$ had loss of carrying angle $11-15^{\circ}$ and 9 patients $(22.5 \%)$ had $>15^{\circ}$ loss of carrying angle developed cubitus varus deformity (Figure 4). In group A, out of 17 (42.5\%) patients, 4 (23.52\%) patients had good results, $5(29.41 \%)$ patients had fair results and $8(47.05 \%)$ children had poor results. In group $\mathrm{B}$, among 5 patients $4(80 \%)$ had excellent outcome and $1(20 \%)$ had fair outcome. In group C, 11 (61.11\%) patients had excellent results, 5 (27.77\%) patients had good results, $1(5.55 \%)$ patients had fair and $1(5.55 \%)$ poor result (Table 4$)$.

\section{DISCUSSION}

The average annual incidence of elbow fractures in childhood was 12 per 10,000. Supracondylar humerus fracture is the most common elbow fracture in children. It constitute about $55 \%$ of all the elbow fractures. ${ }^{7}$ As the skeleton is immature in children, the fractures occur commonly in the first decade of life. The incidence of supracondylar fractures has two peaks, one between 4-5 and other in 5-8 years of age. In this study, majority $70 \%$ of children were in the age group of 4-8 years. In this present study, the mean age of presentation was 6 years. According to Ramsey et al, the mean age of presentation was 7 years. ${ }^{8}$ According to a study done by Andrew et al, the average age of presentation was 6.7 year. ${ }^{5}$ There was male predominance in this study. In a study done by Mazda et al., male predominance was seen just like our study. ${ }^{9}$ In the present study, majority $75 \%$ sustained fractures due to sports related injury. Fransworth et al, in their study $70 \%$ of cases sustained fracture due to fall. ${ }^{10}$ Left sided fracture was seen in $80 \%$ of children in this study as majority of the children have right sided dominance. All the cases reported in our study was extension type of supracondylar fractures, no cases of flexion type reported. According to the literature extension type constitute $97-98 \%$ and flexion type constitute only $2-3 \% .^{11}$

In this study, majority $(56.5 \%)$ of children were operated within 24 hours of injury. According to a study by Ramsey et al, all $100 \%$ cases were operated on the same day of admission. ${ }^{8}$ According to David Skaggs, the average interval of time of injury and operation was 1.4 days in their study. ${ }^{1}$ In the present study, complications were less for children who were operated on the first day then those who were operated on the second and third day of admission. There was statistically significant association between rate of complication and timing of surgery $(p=0.02)$. There was no association between outcome of surgical treatment and timing of surgery.

42.5\% were managed conservatively with closed reduction and POP slab in this study. In a study done by Pham et al, $75.8 \%$ of children with Gartland type IIB and III supracondylar fractures were treated conservatively with Blount's method. The authors had satisfactory outcome of $90 \%$ according to Flynn's criteria and only $2 \%$ of cubitus varus deformity in their study. So according to Pham, Blount's method shows reasonable results and can be followed for type III fractures. ${ }^{12}$ One more study by Muccioli et al also had satisfactory results with Blount's technique. ${ }^{13}$ In the present study, $12.5 \%$ were treated by closed reduction and percutaneous $\mathrm{K}$ wire fixation. In a comparative study done at Serbia, 37 (39.78\%) children who were treated with closed reduction and percutaneous pinning $100 \%$ had satisfactory outcome according to Flynn's criteria (Table 5). ${ }^{14}$ In the present study, majority $45 \%$ of cases were operated by open reduction and percutaneous $\mathrm{K}$ wire fixation. 
Table 5: Comparison between present study and other methods of treating displaced supracondylar fracture.

\begin{tabular}{|lllllll|}
\hline & Author & No. of cases & $\begin{array}{l}\text { Flynn's grading } \\
\text { Excellent } \\
\text { N }(\%)\end{array}$ & $\begin{array}{l}\text { Good } \\
\text { N }(\%)\end{array}$ & $\begin{array}{l}\text { Fair } \\
\text { N }(\%)\end{array}$ & $\begin{array}{l}\text { Poor } \\
\text { N (\%) }\end{array}$ \\
\hline $\begin{array}{l}\text { Conservative } \\
\text { (group A) }\end{array}$ & $\begin{array}{l}\text { Present } \\
\text { study }\end{array}$ & 17 & 0 & $4(23.52)$ & $5(29.41)$ & $8(47.05)$ \\
\hline $\begin{array}{l}\text { Closed reduction and } \\
\text { percutaneous } \\
\text { K wire fixation } \\
\text { (group B) }\end{array}$ & $\begin{array}{l}\text { Present } \\
\text { study }\end{array}$ & 5 & $4(80)$ & 0 & $1(20)$ & 0 \\
\hline $\begin{array}{l}\text { Open reduction and K } \\
\text { wire fixation } \\
\text { (group C) }\end{array}$ & $\begin{array}{l}\text { Present } \\
\text { study }\end{array}$ & 18 & $11(61.11)$ & $5(27.77)$ & $1(5.55)$ & $1(5.55)$ \\
\hline $\begin{array}{l}\text { Conservative } \\
\text { Closed reduction and }\end{array}$ & $\begin{array}{l}\text { Pham al } \\
\text { et }\end{array}$ & 238 & $205(86.13)$ & $21(8.82)$ & $5(2.1)$ & $7(2.94)$ \\
\hline $\begin{array}{l}\text { Ducic } \\
\text { Kercutaneous }\end{array}$ & et al ${ }^{14}$ & 37 & $26(70)$ & $9(24)$ & $2(6)$ & 0 \\
\hline $\begin{array}{l}\text { Open reduction and K } \\
\text { wire fixation }\end{array}$ & Li et al ${ }^{15}$ & 83 & $75(90.36)$ & $3(3.61)$ & $2(2.4)$ & $3(3.61)$ \\
\hline
\end{tabular}

In the study done by Weiland et al, all the 52 displaced supracondylar fractures were treated surgically by open reduction and $\mathrm{K}$ wire fixation. ${ }^{5} \mathrm{In}$ a Chinese retrospective study, all 83 patients who were treated by open reduction and $\mathrm{K}$-wire fixation had $90.4 \%$ excellent results in the treatment outcome evaluated by Flynn criteria (Table 5). ${ }^{15}$ In a study done by Gowda et al, all 50 patients who were treated by open reduction and internal fixation with K-wire had reported $10 \%$ of ulnar nerve palsy and $83.3 \%$ had excellent/good outcome. ${ }^{16}$ In a study done by Mazda et al, $92 \%$ of children who had undergone open reduction with internal fixation had excellent outcome according to Flynn criteria. $^{9}$

In this study, cross $\mathrm{K}$ wire pinning was done in 19 cases and lateral $\mathrm{K}$ wire pinning was done in 4 cases. Cross $\mathrm{K}$ wire pinning offers a good biomechanical stability than unilateral pinning, so most of the cases in our study were operated with cross wire pinning. ${ }^{17}$ In the present study, ulnar nerve palsy was seen in $23.5 \%$ of children who were operated with cross $\mathrm{K}$ wire and $11.7 \%$ patients had iatrogenic radial nerve palsy. All the nerve palsies were neuropraxias which resolved over a period of 3 weeks to 6 months. Ulnar nerve palsy was reported in 1 out of 6 cases in our study with lateral pinning. Superficial pin tract infection was also seen in $17.64 \%$ children with cross wire fixation, which resolved with antibiotics. $68.4 \%$ children had excellent and $26.3 \%$ had good outcome with cross wire pinning in this study. $50 \%$ had fair and $50 \%$ had excellent outcome with lateral wire pinning. There was statistically significant association between excellent/good outcome with cross wire pinning than lateral pinning $(p=0.015)$. According to Gudda et al, there was no significant difference between cross wire and lateral pinning both radiologically and functionally assessed by Flynn's criteria. But cross wire pinning had $6.8 \%$ cases of ulnar palsy which was transient and resolve over a period of 3 weeks' time. Superficial pin infection was seen in both cross wire and lateral pinning in Lokesh study. ${ }^{18}$

In our study, $61.11 \%$ had excellent and $27.77 \%$ had good results in group $\mathrm{C}$ children operated with open reduction and internal fixation. $80 \%$ had excellent results in group B children who were treated with closed reduction and percutaneous $\mathrm{K}$ wire fixation. $47.05 \%$ of group A children had poor results who were treated conservatively with closed reduction and POP slab. There was an association between outcome of treatment and mode of treatment of supracondylar fracture of humerus. There was highly significant association of satisfactory (excellent/good/fair) outcome with surgical treatment than with conservative treatment $(\mathrm{p}=0.0013)$.

\section{CONCLUSION}

Supracondylar fracture of humerus should be operated as early as possible to reduce the rate of complications. The outcome of surgical treatment was better than conservative treatment evaluated in terms of Flynn's criteria. Cross wire pinning was better than lateral pinning in terms of outcome, but the rate of neuropraxias was more with cross wire pinning.

\section{Funding: No funding sources}

Conflict of interest: None declared

Ethical approval: The study was approved by the institutional ethics committee

\section{REFERENCES}

1. Omid R, Choi PD, Skaggs DL. Supracondylar humeral fractures in children. J Bone Joint Surg. 2008;90:1121-32. 
2. Cheng JCY, Lam TP, Maffulli N. Epidemiological features of supracondylar fractures of the humerus in Chinese children. J Pediatr Orthop Part B. 2001;10(1):63-7.

3. Picado VA, Moran G, Moraleda L. Management of supracondylar fractures of the humerus in children. British Editorial Society Bone Joint Surg. 2018;3:526-40

4. Chateau FPW, McIntyre ML. An Analysis of Open Reduction of Irreducible Supracondylar Fractures of the Humerus in Children. Can J Surg. 1998;41(2):112-8.

5. Weiland AJ, Meyer S, Tolo VT, Berg HL, Mueller J. Surgical treatment of displaced supracondylar fractures of the humerus in children. Analysis of fifty-two cases followed for five to fifteen years. J Bone J Surg. 1978;60(5):657-61.

6. Gartland JJ. Management of Supracondylar Fractures of the Humerus in Children. Surg Gynecol Obs. 1959;109(2):145-54.

7. Landin LA, Danielsson LG. Elbow fractures in children: An epidemiological analysis of 589 cases. Acta Orthop. 1986;57(4):309-12.

8. Ramsey RHGJ. Immediate open reduction and internal fixation of severely displaced supracondylar fractures of the humerus in children. Clin Orthop Relat Res. 1973;90:131-2.

9. Mazda K, Boggione C, Fitoussi F, Penneçot GF. Systematic pinning of displaced extension-type supracondylar fractures of the humerus in children. $\mathrm{J}$ Bone J Surg. 2001;83(6):888-93.

10. Farnsworth CL, Silva PD, Mubarak SJ. Etiology of supracondylar humerus fractures. J Pediatr Orthop. 1998;18(1):38-42.

11. Delniotis I, Dionellis P, Gekas CC, Arapoglou D, Tsantekidis D, Goulios V, et al. Flexion-type supracondylar humeral fracture with ulnar nerve injury in children: two case reports and review of the literature. Am J Case Rep. 2020;21:e921293-1e921293-6.
12. Pham TT, Accadbled F, Abid A, Ibnoulkhatib A, Iniguez BX, Wargny M, et al. Gartland types IIB and III supracondylar fractures of the humerus in children: is Blount's method effective and safe. J Shoulder Elb Surg. 2017;26(12):2226-31.

13. Muccioli C, Batti ES, Oborocianu I, Rosello O, Solla F, Chau E, et al. Outcomes of Gartland type III supracondylar fractures treated using Blount's method. Orthop Traumatol Surg Res. 2017;103(7):1121-5.

14. Ducic S, Bumbasirevic M, Radlovic V, Nikic P, Bukumiric Z, Brdar R, et al. Displaced supracondylar humeral fractures in children: Comparison of three treatment approaches. Srp Arh Celok Lek. 2016;144(1-2):46-51.

15. Li M, Xu J, Hu T, Zhang M, Li F. Surgical management of Gartland type III supracondylar humerus fractures in older children: A retrospective study. J Pediatr Orthop Part B. 2019;28(6):530-5.

16. Gowda PM, Mohammed N. A Study of Supracondylar Fractures of Humerus in Children by Open Reduction and Internal Fixation with Kirschner Wires. Indian J Clin Pract. 2014;25(6).

17. Zionts LE, Kellop MHA, Hathaway R. Torsional strength of pin configurations used to fix supracondylar fractures of the humerus in children. $\mathrm{J}$ Bone J Surg. 1994;76(2):253-6.

18. Naik LG, Sharma GM, Badgire KS, Qureshi F, Waghchoure C, Jain V. Cross pinning versus lateral pinning in the management of type III supracondylar humerus fractures in children. J Clin Diagnos Res. 2017;11(8):3-5.

Cite this article as: Vinay N, Manjunatha A, Anand KBS. A comparative study on outcome of conservative and surgical treatment of type III supracondylar fracture of humerus in children. Int $\mathbf{J}$ Res Orthop 2020;6:817-22. 